\title{
Development of a residuum/socket interface simulator for lower limb prosthetics
}

\begin{tabular}{|c|c|}
\hline Journal: & Part H: Journal of Engineering in Medicine \\
\hline Manuscript ID & JOEIM-16-0084.R1 \\
\hline Manuscript Type: & Original article \\
\hline Date Submitted by the Author: & $\mathrm{n} / \mathrm{a}$ \\
\hline Complete List of Authors: & $\begin{array}{l}\text { McGrath, Michael; University of Southampton Faculty of Engineering and } \\
\text { the Environment, Engineering Sciences } \\
\text { Gao, Jianliang; University of Southampton Faculty of Engineering and the } \\
\text { Environment, Engineering Sciences } \\
\text { Tang, Jinghua; University of Southampton Faculty of Engineering and the } \\
\text { Environment, Engineering Sciences } \\
\text { Laszczak, Piotr; University of Southampton Faculty of Engineering and the } \\
\text { Environment, Engineering Sciences } \\
\text { Jiang, Liudi; University of Southampton Faculty of Engineering and the } \\
\text { Environment, Engineering Sciences } \\
\text { Bader, Dan; Southampton University, } \\
\text { Moser, David; Chas A Blatchford and Sons Ltd } \\
\text { Zahedi, Saeed; Chas A Blatchford and Sons Ltd }\end{array}$ \\
\hline Keywords: & Limb Prosthetics, Residuum, Lower Limb, Interface, Simulator, Socket \\
\hline Abstract: & $\begin{array}{l}\text { Mechanical coupling at the interface between lower limb residua and } \\
\text { prosthetic sockets plays an important role in assessing socket fitting and } \\
\text { tissue health. However, most research lab based lower limb prosthetic } \\
\text { simulators to-date have implemented a rigid socket coupling. This study } \\
\text { describes the fabrication and implementation of a lower limb } \\
\text { residuum/socket interface simulator, designed to reproduce the forces and } \\
\text { moments present during the key loading phases of amputee walking. An } \\
\text { artificial residuum made with model bones encased in silicone was used, } \\
\text { mimicking the compliant mechanical loading of a real residuum/socket } \\
\text { interface. A six degree-of-freedom (6DOF) load cell measured the overall } \\
\text { kinetics, having previously been incorporated into an amputee's prosthesis } \\
\text { to collect reference data. } \\
\text { The developed simulator was compared to a setup where a rigid pylon } \\
\text { replaced the artificial residuum. A maximum uniaxial load of } 850 \mathrm{~N} \text { was } \\
\text { applied, comparable to the peak vertical ground reaction force component } \\
\text { during amputee walking. Load cell outputs from both pylon and residuum } \\
\text { setups were compared. During weight acceptance, when including the } \\
\text { artificial residuum, compression decreased by } 10 \% \text {, while, during push off, } \\
\text { sagittal bending and anterior-posterior shear showed a } 25 \% \text { increase and } \\
34 \% \text { decrease, respectively. } \\
\text { Such notable difference by including a compliant residuum further } \\
\text { highlighted the need for such an interface simulator. Subsequently, the } \\
\text { simulator was adjusted to produce key load cell outputs briefly aligning } \\
\text { with those from amputee walking. Force Sensing Resistors (FSRs) were } \\
\text { deployed at load-bearing anatomic locations on the residuum/socket } \\
\text { interface to measure pressures and were compared to those cited in } \\
\text { literature for similar locations. }\end{array}$ \\
\hline
\end{tabular}




\section{Page 1 of 48}

2

3

4

5

6

7

8

9

10

11

12

13

14

15

16

17

18

19

20

21

22

23

24

25

26

27

28

29

30

31

32

33

34

35

36

37

38

39

40

41

42

43

44

45

46

47

48

49

50

51

52

53

54

55

56

57

58

59

60

http://mc.manuscriptcentral.com/(site)

The development of such a novel simulator provides an objective adjunct, using commonly available mechanical test machines. It could potentially be used to provide further insight into socket design, fit and the complex load transfer mechanics at the residuum/socket interface, as well as to evaluate the structural performance of prostheses.

SCHOLARONE $^{\text {m }}$
Manuscripts 
13 Corresponding author email: m.p.mcgrath@southampton.ac.uk

\section{Development of a residuum/socket interface simulator}

4 Michael McGrath ${ }^{1}$, Jianliang Gao ${ }^{1}$, Jinghua Tang ${ }^{1}$, Piotr Laszczak ${ }^{1}$, Liudi Jiang ${ }^{1}$, Dan Bader ${ }^{2}$, $5 \quad$ David Moser $^{3}$ and Saeed Zahedi ${ }^{3}$

6

$7 \quad{ }^{1}$ Faculty of Engineering and the Environment, University of Southampton, Southampton, UK

$8 \quad{ }^{2}$ Faculty of Health Sciences, University of Southampton, Southampton, UK

$9 \quad{ }^{3}$ Chas A. Blatchford \& Sons Ltd., Endolite Technology Centre, Basingstoke, Hampshire, UK 10

Original Article (marked version) 60 
37 socket design, fit and the complex load transfer mechanics at the residuum/socket interface, as

38 well as to evaluate the structural performance of prostheses.

39

\section{Keywords}

41 Lower limb, prosthetics, residuum, socket, interface, simulator 


\section{Introduction}

43 A comfortable, well-fitting socket is integral to the health of an amputee's residuum ${ }^{1}$. In some

44 cases, the residuum will be exposed to excess loads at the residuum/socket interface, leading

45 to the potential development of blisters, skin inflammation and pressure ulcers ${ }^{1-3}$. Currently,

46 prosthetists generally depend on subjective expertise and feedback from the amputee to

47 produce well-fitting sockets. Indeed, there is a general lack of objective means to quantitatively examine how changes of socket design, fit and limb setup may affect residuum tissue loading.

As a consequence, many studies have focused on the measurement of interface stress ${ }^{2,4-7}$

51 using various sensor systems. However, the reported values of interface pressures, for a given anatomic location on a residuum, for example at the popliteal depression, range considerably

53 from $35 \mathrm{kPa}^{2}$ to $244 \mathrm{kPa}^{8}$. This is due, in part, to the large intra-subject variability in amputee

54 residua included in the studies. Indeed, even the residuum of an individual amputee can

55 fluctuate in volume, with values of up to $8 \%{ }^{9}$ depending upon the time of day, the environmental 56 conditions and the time following their amputation ${ }^{10}$, all of which will affect interfacial stress

57 values. Although these factors will clearly influence the clinical evaluation of socket fit, the variation will also hinder valid comparisons of interface measurement systems and socket design approaches. This has motivated the development of lab-based simulators based on 60 international guidelines, typically ISO $10328^{11}$. This standard simplifies the complex loading 61 profile during walking, into two discrete loading events, termed Conditions 1 and 2 . These 62 conditions simulate the forces and moments associated with the prosthetic during the weight 63 acceptance' (WA) and 'push-off'' (PO) phases of walking, respectively, corresponding with the 64 two peaks in the vertical ground reaction force (GRF). However, ISO 10328 was designed to 65 assess the structural integrity of the components ${ }^{12}$, as opposed to evaluation of loading at the 
residuum/socket interface, thus it is often implemented with a rigid socket coupling ${ }^{13}$. A gait

67 simulator using industrial robotics has recently been reported ${ }^{14}$, in which objective pressure measurements at the residuum/socket interface were conducted and correlated with the levels of comfort. However, the large size and cost of such a specific system, significantly limit its wide applicability. Accordingly there is a need to provide a realistic, relatively low-cost simulator to be used in conjunction with mechanical test machines, which are readily available in research labs.

This paper describes the design and fabrication of a lower limb prosthetic simulator that can provide a representation of the residuum/socket interface by including an artificial residuum with bony prominences incorporated within a soft tissue analogue. It was also designed to accommodate the key peak loading events during gait, equivalent to the WA and PO phases of walking. The development of such a simulator and associated test arrangements provide effective and practical approaches to build lab-based tools, which offer potential in assessing socket fit, interface stress and their dependence on prosthetic components, alignment etc.

\section{Methods}

\section{Simulator development}

Figure 1a shows a schematic of the trans-tibial simulator design with key components identified,

84 including a trans-tibial artificial residuum, matching socket, a six degree-of-freedom (6DOF) load cell and upper and lower alignment plates. The simulator was designed to be compatible with a

86 uniaxial mechanical test machine (8800 series, Instron Ltd., High Wycombe, UK). Ball-and-

87 socket joints were used at the upper and lower points of load application to allow for movement

88 of the simulator during compression, without generating bending forces and moments in the test 
machine. Attached to each of these were alignment plates, which can be arranged to produce WA and PO phases. Since it has been shown that prosthetic feet provide limited propulsion in the PO phase ${ }^{15}$, the lack of a foot in this simulator was not envisaged to detrimentally affect the comparative results. With the exception of the residuum/socket interface and the ball-andsocket joints, as shown in Figure 1a, all other components were linked via rigid connectors. The prosthetic socket was aligned 'neutrally' so that the upper plate was parallel with the bottom plate.

A truncated trans-tibial knee joint was encased in silicone to form the trans-tibial artificial residuum (Figure 1b-c). Following surgical guidelines for trans-tibial amputations ${ }^{16}$, model bones (UK3BS, Somerset, UK) were cut to the desired size. In particular, the sectioned tibia was approximately $110 \mathrm{~mm}$ distal to the tibial tubercle, while fibula was obliquely cut to a length of $90 \mathrm{~mm}$ from fibula end to fibula head. These two bones were then joined together, with a model femur and patella, using an industrial adhesive to form a rigid, neutral-angled knee joint (Figure 1b). A matching anatomical moulding tool, created by a senior prosthetist, was subsequently draped over the cast of a trans-tibial amputee, measuring $340 \mathrm{~mm}$ in circumference at the patella tendon, with a residuum length of $150 \mathrm{~mm}$ (Figure 1c). The mould was used to encase

106 the truncated bones with purpose-made silicone material (Bentley Advanced Materials, Feltham, UK), with a compressive modulus of $\sim 146 \mathrm{kPa}$. This was designed to represent a homogenous approximation of soft tissues, which at the lower limb residuum have been reported to range from 50 to $150 \mathrm{kPa}^{17-19}$. The use of silicone has also been proven successful 110 for simulating tissue while maintaining constant volume ${ }^{20}$ and thus has been used to develop residuum limb manikins ${ }^{21}$. There are also practical advantages of using silicone as opposed to 112 biological materials, such as animal flesh or cadaveric residuum, which would need to be 
preserved. In addition, silicone can be easily moulded to comply with the complex shapes of the truncated bones and residuum, thus reproducibly simulating the real scenario of the

115 residuum/socket interface.

116

117 An alignment jig was used during the moulding process to ensure the truncated knee alignment, within the residuum, based on the surgical guidelines ${ }^{16}$ (Figure $1 \mathrm{~b}$ ). A matching total surface bearing, pin-lock suspension socket was made for the residuum, by a senior prosthetist, using standard casting and rectification procedures. The artificial residuum was covered with a soft silicone liner (Chas A Blatchford \& Sons, Basingstoke, UK), utilising the pin lock suspension, before being placed within the matching socket in order to represent the real scenario at the interface.

124

The 6DOF load cell represented an integral part of the simulator. Its axes were aligned to the anatomical planes (Figure 1d), providing simultaneous measurement of the forces in three axes i.e. compression, anterior-posterior $(\mathrm{AP})$ shear and medial-lateral $(\mathrm{ML})$ shear, and the moments acting around these axes i.e. axial torque, sagittal bending and coronal bending. The load cell was first incorporated into an amputee's prosthetic limb to collect reference data during walking.

The load cell data from the amputee were then used to provide benchmarks for the kinetic parameters of the simulator, in a similar manner to that previously reported ${ }^{22-24}$

132

\section{Load cell reference data from an amputee}

134 Measurements were made with the load cell, during a series of level walks at a self-selected speed by a male amputee volunteer (28 years old, $75 \mathrm{~kg}$ ). The data were collected and provided 
137 addition, the participant was asked to walk over a ground-mounted force plate (Kistler Group, 138 Winterthur, Switzerland) with a view to obtaining peak values of vertical GRF for WA and PO 139 phases. The mean peak vertical GRF values for WA and PO phases were approximately $850 \mathrm{~N}$ each, which was used to as the load input to the uniaxial test machine during simulator tests. Under this load, mimicking GRF, three load cell channels i.e. compression, sagittal bending and AP shear, were selected as guidance for simulator tuning, since they are the key kinetic components in the sagittal plane. It is worth noting that the vertical component of GRF would vary if the simulator was to be designed based on different amputees.

The vertical GRF is a key factor affecting the biomechanics at the residuum/socket interface ${ }^{25}$.

147 In this work, although the simulator residuum was of different geometry to that of the amputee involved in the walking test, the procedure has been simplified by adopting the vertical GRF as input for the test machine load, while the peak values of the three key load cell outputs (compression, sagittal bending and AP shear) provided approximate guidance for the simulator tuning, with a view to briefly replicating the interface biomechanics.

152

\section{Simulator tuning}

Figure 2 illustrates how the simulator generated the forces and moments of the two phases.

Upmost care was taken to ensure the location of the load cell in the simulator was equivalent to that used during amputee walking tests. Taking the centre of the load cell as the reference frame origin (red dot in Figure 2), a central axis runs along the length of the prosthetic (blue dashed line in Figure 2). The simulator is designed to work on uniaxial test machines and as a consequence, the line of load application (red solid line in Figure 2) runs in a straight line from 
lower plate and the test machine. The line of load application is decomposed onto a twodimensional plane (i.e. sagittal and coronal), as shown by the red dotted lines in Figure $2 a$ and b, respectively. The relative position of the force (red dotted line) in a given plane to the central axis (blue dashed line), effectively determines forces and moments measured by the load cell. The planar angle ( $\theta_{\text {cor }}$ - black arc in Figure $\left.2 a\right)$ between the in-plane force and central axis are defined as $\theta_{\text {cor }}($ Figure $2 a)$ and $\theta_{\text {sag }}$ (Figure $\left.2 b\right)$, respectively. $\theta_{\text {cor }}$ determines how the force can be further decomposed into the compression and $\mathrm{ML}$ shear, while $\theta_{\text {sag }}$ determines how the force line in Figure 2a) from the force in the coronal plane (red dotted line in Figure 2a) to the the sagittal plane is shown in Figure 2b. Altering the relative positions between the upper and collected from the amputee tests.

Testing protocol

In order to investigate the difference between rigid and compliant socket couplings, initially, a rigid aluminium prosthetic pylon (Figure 3a), of the same length $(340 \mathrm{~mm})$ as that of the artificial residuum, was used in place of the residuum on the simulator. The approximate peak vertical GRF obtained during the amputee walking test was used as an input to define a uniaxial compressive load of $850 \mathrm{~N}$ applied to the pylon simulator. The approximate ranges taken from the three key load channels during the amputee walking test were used as guidance, by which to assist the tuning of the simulator. The ball-and-socket joints, between the upper and lower plates and the test machine (Figure 1), allowed rotation to ensure that no damaging moments 
185

could be transferred to the test machine. This tuning was performed for both WA and PO phases, respectively. Subsequently, the pylon was replaced by the artificial residuum (Figure $3 \mathrm{~b}-\mathrm{c})$ and simulator was arranged identically to the respective pylon tests. The compression test was performed and the load cell outputs recorded. By comparing all six channels load cell outputs between pylon and artificial residuum scenarios, the effect of the compliant residuum/socket interface to the kinetics were studied.

Further testing was performed to showcase one of the potential applications using such a lab based simulator, i.e. studies of interface stresses during WA and PO phases. Force Sensing Resistors (FSRs) (Interlink Electronics Inc., Westlake Village, CA, USA) were located at the key anatomical loading sites ${ }^{4,5,7}$, namely patella tendon, popliteal depression and fibula head (Figure $3 d$ ) on the artificial residuum. The artificial residuum simulator was then tuned so that its key load cell outputs briefly represented similar ranges to those measured during the amputee walking test. Particular attention was made of the measurements in the sagittal plane (e.g. compression, sagittal bending and AP shear) and, in particular, the compression output. The sagittal plane incorporates the vertical direction, thus the kinetics which act to support the body's centre of mass (COM), and the direction of progression, thus the kinetics which act to propel COM forward. The WA and PO phases are the points in the gait cycle where the force required to support the COM (the vertical component of GRF) is at a maximum and the compression output measures the largest components of these supporting forces. Subsequently, pressure measurements from FSRs were recorded and compared with counterparts reported in literature. 


\section{Results}

Rigid vs Compliant socket coupling

210 Table 1 shows the mean peak values from the load cell outputs, obtained from the pylon and

211 artificial residuum simulator setups, respectively, while the positions of the upper and lower

212 plates were kept the same.

213

214 It was clear that the data for the pylon and artificial residuum simulators showed differences in

215 key outputs (Table 1). For example, for the WA phase, the compression force on the load cell

216 was $871 \mathrm{~N}$ for the pylon setup and $787 \mathrm{~N}$ for the artificial residuum setup, representing an

217 approximate $10 \%$ reduction when using a compliant socket coupling. For the PO phase, the

218 sagittal bending was $-56 \mathrm{Nm}$ for the pylon and $-70 \mathrm{Nm}$ for the artificial residuum, representing

219 approximately a $25 \%$ increase in magnitude. Also in the PO phase, AP shear was $157 \mathrm{~N}$ for the

220 pylon but only $104 \mathrm{~N}$ for the residuum, approximately a $34 \%$ reduction (Table 1 ).

There were also large differences in the other load cell outputs. In the WA phase, the ML shear was $-45 \mathrm{~N}$ for the pylon and $-57 \mathrm{~N}$ for the residuum, representing a difference of $27 \%$. In the PO phase, the corresponding values were $-45 \mathrm{~N}$ and $-60 \mathrm{~N}$, representing an approximate $33 \%$ difference. Also in the PO phase, coronal bending changed from $-7 \mathrm{Nm}$ to $-12 \mathrm{Nm}$; approximately a $71 \%$ change (Table 1$)$.

Residuum pistoning is a well-recognised feature associated with lower limb amputees ${ }^{26}$. The displacement output from the uniaxial test machine was approximated to a measure of the 
were rigid), when $850 \mathrm{~N}$ was applied to the artificial residuum maximum vertical displacements of approximately $8 \pm 1 \mathrm{~mm}$ and $12 \pm 1 \mathrm{~mm}$, were recorded for WA and PO phases, respectively.

Interface pressure measurement using the developed simulator

Figure 4 shows a comparison of the peak values on three key load cell outputs during the amputee walking test and those measured on the tuned artificial residuum simulator. The focus of the tuning was to briefly achieve approximate sagittal plane kinetics, in particular compression output, which was close to the amputee test values. This output (Figure 4a) was reproduced to within $7 \%$ difference for both the WA and PO phases.

240

Table 2 summarises the ranges of peak pressure measurements recorded from the FSRs when applying a uniaxial load up to a maximum of $850 \mathrm{~N}$, to the artificial residuum simulator. These are compared with reported data by Yeung et al. ${ }^{4}$, adjusting for an amputee of approximately

\section{Discussion}

Initially, both the pylon and the residuum simulators had the same upper and lower plate alignments, therefore any differences in load cell outputs, as shown in Table 1, were solely attributed to the presence of the compliant socket coupling introduced by the inclusion of artificial residuum. The residuum consists of silicone mimicking compliant tissue characteristics which, to a certain degree, permit a degree of deformation at the interface. As the uniaxial load was increased to its maximum value of $850 \mathrm{~N}$, the residuum could rotate within the socket, similar to real amputee scenarios ${ }^{27}$. Rotation in the sagittal plane could affect the three key load 
254 cell outputs (compression, sagittal bending and AP shear) by effectively changing the planar 255 angle between the line of load application, when decomposed onto the sagittal plane, and the 256 load cell central axis $\left(\theta_{\text {sag }}-\right.$ shown by the black arc in Figure $\left.2 b\right)$. This, in turn, meant that the sagittal moment arm changed (black solid line in Figure 2b). During the WA phase, this rotation increased $\theta_{\text {sag, }}$ in a direction anterior to the central axis (blue dashed line in Figure 2), resulting in a relative change in the nature of the load applied in terms of the compression and shear axes. This was reflected by an increase in magnitude for AP shear, from $-105 \mathrm{~N}$ for the pylon to $122 \mathrm{~N}$ for the residuum and a correspondent decrease in the compression value, from $871 \mathrm{~N}$ for the pylon to $787 \mathrm{~N}$ for the residuum. During the PO phase, the rotation of the residuum in the sagittal plane acted to increase compression (from $886 \mathrm{~N}$ for the pylon to $897 \mathrm{~N}$ for the residuum) while decrease AP shear (from $157 \mathrm{~N}$ for the pylon to $104 \mathrm{~N}$ for the residuum). The sagittal bending also increased in magnitude during $\mathrm{PO}$ (from $-56 \mathrm{~N}$ for the pylon to $-70 \mathrm{~N}$ for the residuum). This was a result of the rotation effectively increasing the length of the sagittal bending moment arm (black solid line in Figure 2).

Possible rotation in the coronal plane during the WA and PO phases could have caused changes in other load cell outputs. In this case, the rotation was in the same direction for both phases, since the line of load application was always medial at the upper plate, relative to the reference frame origin (red dot in Figure 2). This led to an increase in angle between the line of load application, when decomposed onto the coronal plane, and the load cell central axis $\left(\theta_{\text {cor }}-\right.$ black arc in Figure 2a). Consequently, the magnitude of ML shear increased in both phases (-

$27545 \mathrm{~N}$ and $-45 \mathrm{~N}$ for the pylon, compared to $-57 \mathrm{~N}$ and $-60 \mathrm{~N}$ for the residuum - see Table 1). It also 276 increased the moment arm in coronal bending (black solid line in Figure 2a), resulting in an 
277 increase, in the PO phase, in the magnitude of coronal bending between the pylon $(-7 \mathrm{Nm})$ and

278 the residuum $(-12 \mathrm{Nm})$ simulators.

279

In order to create a simulator setup that mimicked interface dynamics from real amputee walking, the artificial residuum simulator was tuned, with a view to briefly approximate the three key peak load cell outputs to the amputee test. During the simulator tuning, the priority was to focus on compression values, because this axis provides the largest contribution to COM support (Figure 4a), and at the same time ensuring outputs in sagittal bending and AP shear outputs were in similar ranges for amputee tests and simulator setups (Figure $4 \mathrm{~b}$ and c). Figure 4 shows that AP shear during PO presented greatest difference between the amputee test $(113 \mathrm{~N})$ and the simulator $(178 \mathrm{~N})$. This is likely because that only the upper and lower plates were used to tune the simulator, while in real amputee scenarios, other effects, such as socket fit and alignment, could also affect the kinetics. Thus, for future work, more comprehensive means to tune the simulator will be investigated by incorporating these effects. Nonetheless, for this study, the simulator was set up, as show in Figure 4, to briefly reproduce amputee walking kinetics so that interface pressure could be studied. 
popliteal depression ${ }^{28}(144 \sim 165 \mathrm{kPa})$. The pressure at the fibula head is affected by the mediallateral motion of the body's COM during walking. During WA phase, the body COM is moving laterally ${ }^{29}$, increasing pressure on the fibula head of the residuum $(75 \sim 160 \mathrm{kPa})$. By contrast, during the $\mathrm{PO}$ phase, this pressure is reduced $(100 \sim 137 \mathrm{kPa})$, as the COM moves in a medial direction $^{29}$.

306

The pressure ranges are similar to those previously reported by Yeung et $\mathrm{al}^{4}$, adapted for an amputee of similar weight (Table 2). Any minor differences could be attributed to the fact that the silicone based artificial residuum may not have proved an exact representation of the soft

\section{The amount of pistoning measured for the artificial residuum during loaded conditions was} approximately $8 \mathrm{~mm}$ and $12 \mathrm{~mm}$ for WA and PO phases, respectively. These values are of similar magnitude to that $(6 \pm 4 \mathrm{~mm})$ previously reported ${ }^{26}$. A degree of variation in displacement range would be predicted as this measure is dependent on many factors, such as socket fit, fluctuations of residuum geometry and volume and prosthetic component alignments etc. It is envisaged that, aside from the total surface bearing socket utilized in this work, it would also be 
interesting to repeat the protocol using other socket and liner types, such as a patella tendon bearing (PTB) socket and a foam liner, with a view to comparing interface biomechanics. It is worth noting that, in comparison to the previously reported simulators, such as the robotic gait simulator $^{14}$, the present system was designed specifically to replicate the WA and PO phases of the gait. Thus, its current design will not reflect temporal changes in loading throughout the complete gait cycle. However, in this work, WA and PO phases were chosen based on ISO 10328 , as GRF reaches peak values in these phases and consequently extreme levels of load are exerted at the residuum/socket interface. The compatibility of the simulator with commonly available test machines facilitates its adoption in a wide range of lab-based tests and studies.

It is thus envisaged that the approach adopted in the development of a residuum/socket interface simulator, could be potentially beneficial to both researchers and clinicians. Such simulators could be applied in lab settings to assess the biomechanical state at the critical residuum/socket interface for lower limb amputees. For example, these results could be used in conjunction with human studies to provide more information regarding interface dynamics. This could then be exploited in Finite Element Analyses to provide a more comprehensive predictive model. Such a simulator could also be used to evaluate socket fit and prosthetic component performance in the clinical setting. Patient-specific artificial residua could be fabricated and the simulator could be used to identify the long-term impact of a particular socket design.

\section{Conclusion}

346 This work presents a practical approach for the design, fabrication and testing of a lower limb 347 prosthetic simulator, which has the potential to predict biomechanical conditions at the 
348 residuum/socket interface. Our results suggest that such a simulator can be 'tuned' to simulate

349 walking in stance phase and interface mechanics for specific lower limb amputees. In general,

350 such simulators could be potentially exploited as a lab-based tool to assess interface

351 biomechanics, socket fit, tissue viability etc. without the extensive involvement of amputee participants. This could be particularly advantageous for the assessment of amputees with various comorbidities e.g. gait pathologies and peripheral neuropathy.

354

\section{Acknowledgements}

356 The authors would like to thank the UK Medical Research Council (MR/L013096/1) for providing

357 funding and also members of Chas A Blatchford \& Sons Ltd. including Joe McCarthy, Richard

358 Bradbury and Ana Gallego for their help with the fabrication of the artificial residuum and socket

359 for the simulator. All data supporting this study are openly available from the University of

360 Southampton repository at http://doi.org/10.5258/SOTON/403884.

361

362 Conflicts of interest

363 There are no conflicts of interest in this study. 364

365 Word count (Introduction-Conclusion): 4233 


\section{References}

367 1. Dudek NL, Marks MB, Marshall SC and Chardon JP. Dermatologic conditions 368 associated with use of a lower-extremity prosthesis. Archives of Physical Medicine and 369 Rehabilitation. 2005; 86: 659-63.

370 2. Sanders JE, Lam D, Dralle AJ and Okumura R. Interface pressures and shear stresses 371 at thirteen socket sites on two persons with transtibial amputation. Journal of Rehabilitation 372 Research and Development. 1997; 34: 19-43.

373 3. Bader DL, Bouten C, Colin D and Oomens CW. Pressure Ulcer Research: current and 374 future perspectives. Berlin, Heidelberg: Springer Science \& Business Media, 2005.

375 4. Yeung LF, Leung AK, Zhang M and Lee WC. Effects of long-distance walking on 376 socket-limb interface pressure, tactile sensitivity and subjective perceptions of trans-tibial 377 amputees. Disability and Rehabilitation. 2013; 35: 888-93.

378 5. Zahedi S. Lower Limb Prosthetic Research In The 21st Century, Atlas of Prosthetics. 3792001.

380 6. Laszczak P, Jiang L, Bader DL, Moser D and Zahedi S. Development and validation of 381 a 3D-printed interfacial stress sensor for prosthetic applications. Medical Engineering \& Physics. $382 \quad 2015 ; 37: 132-7$.

383 7. Zhang M, Turner-Smith AR, Tanner A and Roberts VC. Clinical investigation of the 384 pressure and shear stress on the trans-tibial stump with a prosthesis. Medical Engineering \& 385 Physics. 1998; 20: 188-98.

386 8. Convery P and Buis AW. Conventional patellar-tendon-bearing (PTB) socket/stump 387 interface dynamic pressure distributions recorded during the prosthetic stance phase of gait of a 388 trans-tibial amputee. Prosthetics \& Orthotics International. 1998; 22: 193-8. 
390 investigation of residual-limb fluid volume changes within one day. Journal of Rehabilitation Research and Development. 2012; 49: 1467-78. 10. Sanders JE and Fatone S. Residual limb volume change: Systematic review of measurement and management. Journal of Rehabilitation Research and Development. 2011; 48: $949-86$.

395 11. British Standards Institution. Prosthetics - Structural testing of lower-limb prostheses 396 Requirements and test methods. 2006.

397 12. Bonnet X, Pillet H, Fodé P, Lavaste F and Skalli W. Finite element modelling of an 398 energy-storing prosthetic foot during the stance phase of transtibial amputee gait. Proceedings 399 of the Institution of Mechanical Engineers, Part H: Journal of Engineering in Medicine. 2012; $400 \quad 226: 70-5$

401 13. Neo LD, Lee PV and Goh JC. Principal structural testing of trans-tibial prosthetic 402 assemblies: specimen preparation. Prosthetics \& Orthotics International. 2000; 24: 241-5.

403 14. De Raeve E, Saey T, Muraru L and Peeraer L. The use of a robotic gait simulator for 404 the development of an alignment tool for lower limb prostheses. J Foot Ankle Res. 2014; 7: 1-2.

405 15. Crimin A, McGarry A, Harris EJ and Solomonidis SE. The effect that energy storage 406 and return feet have on the propulsion of the body: A pilot study. Proceedings of the Institution 407 of Mechanical Engineers, Part H: Journal of Engineering in Medicine. 2014; 228: 908-15.

408 16. King M, Bewes P, Awori N, et al. Primary Surgery: Trauma. Oxford, UK: Oxford Medical 409 Publications, 1987.

410 17. Krouskop TA, Dougherty DR and Vinson FS. A pulsed Doppler ultrasonic system for 411 making noninvasive measurements of the mechanical properties of soft tissue. Journal of 412 Rehabilitation Research and Development. 1987; 24: 1-8. 
413 18. Mak AF, Liu GH and Lee SY. Biomechanical assessment of below-knee residual limb 414 tissue. Journal of Rehabilitation Research and Development. 1994; 31: 188-98.

415 19. Malinauskas M, Krouskop TA and Barry PA. Noninvasive measurement of the stiffness 416 of tissue in the above-knee amputation limb. Journal of Rehabilitation Research and 417 Development. 1989; 26: 45-52.

418 20. Kerdok AE, Cotin SM, Ottensmeyer MP, Galea AM, Howe RD and Dawson SL. Truth 419 cube: Establishing physical standards for soft tissue simulation. Medical Image Analysis. 2003; $420 \quad 7: 283-91$.

421 21. McGarry A, McHugh B, Duers J and Buis AW. Design of manikin for testing of residual422 limb shape-capture method: Technical note. Journal of Rehabilitation Research and 423 Development. 2011; 48.

424 22. Lowe P. Knee mechanism performance in amputee activity. Ph. D. Thesis (2nd. edn.) 425 University of Strathclyde (May 1969), 1969.

426 23. Berme N, Lawes P, Solomonidis S and Paul JP. A Shorter Pylon Transducer for 427 Measurement of Prosthetic Forces and Moments during Amputee Gait. Engineering in $428 \quad$ Medicine. 1975; 4: 6-8.

429 24. Cunningham DM and Brown GW. Two devices for measuring the forces acting on the 430 human body during walking. Proceedings of the Society for Experimental Stress Analysis. 1952; 431 9: 75-90.

432 25. Wolf SI, Alimusaj M, Fradet L, Siegel J and Braatz F. Pressure characteristics at the 433 stump/socket interface in transtibial amputees using an adaptive prosthetic foot. Clinical 434 Biomechanics. 2009; 24: 860-5.

435 26. Klute GK, Berge JS, Biggs W, Pongnumkul S, Popovic Z and Curless B. Vacuum436 Assisted Socket Suspension Compared With Pin Suspension for Lower Extremity Amputees: 
437 Effect on Fit, Activity, and Limb Volume. Archives of Physical Medicine and Rehabilitation. $438 \quad 2011 ; 92: 1570-5$.

439 27. Tang J, McGrath M, Laszczak P, et al. Characterisation of dynamic couplings at lower 440 limb residuum/socket interface using 3D motion capture. Medical Engineering \& Physics. 2015; $441 \quad 37(12): 1162-8$.

442 28. Jia X, Zhang M and Lee WCC. Load transfer mechanics between trans-tibial prosthetic 443 socket and residual limb_-dynamic effects. Journal of Biomechanics. 2004; 37: 1371-7.

$44429 . \quad K$ Kirtley C. Clinical Gait Analysis - Theory and Practice. Edinburgh: Churchill-Livingstone, 4452006.

446 


\title{
Development of a residuum/socket interface simulator for lower limb prosthetics
}

\author{
Michael McGrath ${ }^{1}$, Jianliang Gao ${ }^{1}$, Jinghua Tang ${ }^{1}$, Piotr Laszczak ${ }^{1}$, Liudi Jiang ${ }^{1}$, Dan Bader ${ }^{2}$, \\ David Moser ${ }^{3}$ and Saeed Zahedi ${ }^{3}$ \\ ${ }^{1}$ Faculty of Engineering and the Environment, University of Southampton, Southampton, UK \\ ${ }^{2}$ Faculty of Health Sciences, University of Southampton, Southampton, UK \\ ${ }^{3}$ Chas A. Blatchford \& Sons Ltd., Endolite Technology Centre, Basingstoke, Hampshire, UK
}

\section{Original Article}

Corresponding author email: m.p.mcgrath@southampton.ac.uk 


\section{Abstract}

Mechanical coupling at the interface between lower limb residua and prosthetic sockets plays an important role in assessing socket fitting and tissue health. However, most research lab based lower limb prosthetic simulators to-date have implemented a rigid socket coupling. This study describes the fabrication and implementation of a lower limb residuum/socket interface simulator, designed to reproduce the forces and moments present during the key loading phases of amputee walking. An artificial residuum made with model bones encased in silicone was used, mimicking the compliant mechanical loading of a real residuum/socket interface. A six degree-of-freedom (6DOF) load cell measured the overall kinetics, having previously been incorporated into an amputee's prosthesis to collect reference data.

The developed simulator was compared to a setup where a rigid pylon replaced the artificial residuum. A maximum uniaxial load of $850 \mathrm{~N}$ was applied, comparable to the peak vertical ground reaction force component during amputee walking. Load cell outputs from both pylon and residuum setups were compared. During weight acceptance, when including the artificial residuum, compression decreased by $10 \%$, while, during push off, sagittal bending and anteriorposterior shear showed a $25 \%$ increase and $34 \%$ decrease, respectively.

Such notable difference by including a compliant residuum further highlighted the need for such an interface simulator. Subsequently, the simulator was adjusted to produce key load cell outputs briefly aligning with those from amputee walking. Force Sensing Resistors (FSRs) were deployed at load-bearing anatomic locations on the residuum/socket interface to measure pressures and were compared to those cited in literature for similar locations.

The development of such a novel simulator provides an objective adjunct, using commonly available mechanical test machines. It could potentially be used to provide further insight into 
socket design, fit and the complex load transfer mechanics at the residuum/socket interface, as well as to evaluate the structural performance of prostheses.

\section{Keywords}

Lower limb, prosthetics, residuum, socket, interface, simulator 


\section{Introduction}

A comfortable, well-fitting socket is integral to the health of an amputee's residuum ${ }^{1}$. In some cases, the residuum will be exposed to excess loads at the residuum/socket interface, leading to the potential development of blisters, skin inflammation and pressure ulcers ${ }^{1-3}$. Currently, prosthetists generally depend on subjective expertise and feedback from the amputee to produce well-fitting sockets. Indeed, there is a general lack of objective means to quantitatively examine how changes of socket design, fit and limb setup may affect residuum tissue loading.

As a consequence, many studies have focused on the measurement of interface stress ${ }^{2,4-7}$ using various sensor systems. However, the reported values of interface pressures, for a given anatomic location on a residuum, for example at the popliteal depression, range considerably from $35 \mathrm{kPa}^{2}$ to $244 \mathrm{kPa}^{8}$. This is due, in part, to the large intra-subject variability in amputee residua included in the studies. Indeed, even the residuum of an individual amputee can fluctuate in volume, with values of up to $8 \%{ }^{9}$ depending upon the time of day, the environmental conditions and the time following their amputation ${ }^{10}$, all of which will affect interfacial stress values. Although these factors will clearly influence the clinical evaluation of socket fit, the variation will also hinder valid comparisons of interface measurement systems and socket design approaches. This has motivated the development of lab-based simulators based on international guidelines, typically ISO $10328^{11}$. This standard simplifies the complex loading profile during walking, into two discrete loading events, termed Conditions 1 and 2 . These conditions simulate the forces and moments associated with the prosthetic during the weight acceptance' (WA) and 'push-off"' (PO) phases of walking, respectively, corresponding with the two peaks in the vertical ground reaction force (GRF). However, ISO 10328 was designed to assess the structural integrity of the components ${ }^{12}$, as opposed to evaluation of loading at the 
residuum/socket interface, thus it is often implemented with a rigid socket coupling ${ }^{13}$. A gait simulator using industrial robotics has recently been reported ${ }^{14}$, in which objective pressure measurements at the residuum/socket interface were conducted and correlated with the levels of comfort. However, the large size and cost of such a specific system, significantly limit its wide applicability. Accordingly there is a need to provide a realistic, relatively low-cost simulator to be used in conjunction with mechanical test machines, which are readily available in research labs.

This paper describes the design and fabrication of a lower limb prosthetic simulator that can provide a representation of the residuum/socket interface by including an artificial residuum with bony prominences incorporated within a soft tissue analogue. It was also designed to accommodate the key peak loading events during gait, equivalent to the WA and PO phases of walking. The development of such a simulator and associated test arrangements provide effective and practical approaches to build lab-based tools, which offer potential in assessing socket fit, interface stress and their dependence on prosthetic components, alignment etc.

\section{Methods}

\section{Simulator development}

Figure 1a shows a schematic of the trans-tibial simulator design with key components identified, including a trans-tibial artificial residuum, matching socket, a six degree-of-freedom (6DOF) load cell and upper and lower alignment plates. The simulator was designed to be compatible with a uniaxial mechanical test machine (8800 series, Instron Ltd., High Wycombe, UK). Ball-andsocket joints were used at the upper and lower points of load application to allow for movement of the simulator during compression, without generating bending forces and moments in the test 
machine. Attached to each of these were alignment plates, which can be arranged to produce WA and PO phases. Since it has been shown that prosthetic feet provide limited propulsion in the PO phase ${ }^{15}$, the lack of a foot in this simulator was not envisaged to detrimentally affect the comparative results. With the exception of the residuum/socket interface and the ball-andsocket joints, as shown in Figure 1a, all other components were linked via rigid connectors. The prosthetic socket was aligned 'neutrally' so that the upper plate was parallel with the bottom plate.

A truncated trans-tibial knee joint was encased in silicone to form the trans-tibial artificial residuum (Figure 1b-c). Following surgical guidelines for trans-tibial amputations ${ }^{16}$, model bones (UK3BS, Somerset, UK) were cut to the desired size. In particular, the sectioned tibia was approximately $110 \mathrm{~mm}$ distal to the tibial tubercle, while fibula was obliquely cut to a length of $90 \mathrm{~mm}$ from fibula end to fibula head. These two bones were then joined together, with a model femur and patella, using an industrial adhesive to form a rigid, neutral-angled knee joint (Figure 1b). A matching anatomical moulding tool, created by a senior prosthetist, was subsequently draped over the cast of a trans-tibial amputee, measuring $340 \mathrm{~mm}$ in circumference at the patella tendon, with a residuum length of $150 \mathrm{~mm}$ (Figure 1c). The mould was used to encase the truncated bones with purpose-made silicone material (Bentley Advanced Materials, Feltham, UK), with a compressive modulus of $\sim 146 \mathrm{kPa}$. This was designed to represent a homogenous approximation of soft tissues, which at the lower limb residuum have been reported to range from 50 to $150 \mathrm{kPa}^{17-19}$. The use of silicone has also been proven successful for simulating tissue while maintaining constant volume ${ }^{20}$ and thus has been used to develop residuum limb manikins ${ }^{21}$. There are also practical advantages of using silicone as opposed to biological materials, such as animal flesh or cadaveric residuum, which would need to be 
preserved. In addition, silicone can be easily moulded to comply with the complex shapes of the truncated bones and residuum, thus reproducibly simulating the real scenario of the residuum/socket interface.

An alignment jig was used during the moulding process to ensure the truncated knee alignment, within the residuum, based on the surgical guidelines ${ }^{16}$ (Figure 1b). A matching total surface bearing, pin-lock suspension socket was made for the residuum, by a senior prosthetist, using standard casting and rectification procedures. The artificial residuum was covered with a soft silicone liner (Chas A Blatchford \& Sons, Basingstoke, UK), utilising the pin lock suspension, before being placed within the matching socket in order to represent the real scenario at the interface.

The 6DOF load cell represented an integral part of the simulator. Its axes were aligned to the anatomical planes (Figure 1d), providing simultaneous measurement of the forces in three axes i.e. compression, anterior-posterior (AP) shear and medial-lateral (ML) shear, and the moments acting around these axes i.e. axial torque, sagittal bending and coronal bending. The load cell was first incorporated into an amputee's prosthetic limb to collect reference data during walking. The load cell data from the amputee were then used to provide benchmarks for the kinetic parameters of the simulator, in a similar manner to that previously reported $22-24$

\section{Load cell reference data from an amputee}

Measurements were made with the load cell, during a series of level walks at a self-selected speed by a male amputee volunteer ( 28 years old, $75 \mathrm{~kg}$ ). The data were collected and provided by Chas A Blatchford \& Sons, in accordance with the tenets of the Declaration of Helsinki. In 
addition, the participant was asked to walk over a ground-mounted force plate (Kistler Group, Winterthur, Switzerland) with a view to obtaining peak values of vertical GRF for WA and PO phases. The mean peak vertical GRF values for WA and PO phases were approximately $850 \mathrm{~N}$ each, which was used to as the load input to the uniaxial test machine during simulator tests. Under this load, mimicking GRF, three load cell channels i.e. compression, sagittal bending and AP shear, were selected as guidance for simulator tuning, since they are the key kinetic components in the sagittal plane. It is worth noting that the vertical component of GRF would vary if the simulator was to be designed based on different amputees.

The vertical GRF is a key factor affecting the biomechanics at the residuum/socket interface ${ }^{25}$. In this work, although the simulator residuum was of different geometry to that of the amputee involved in the walking test, the procedure has been simplified by adopting the vertical GRF as input for the test machine load, while the peak values of the three key load cell outputs (compression, sagittal bending and AP shear) provided approximate guidance for the simulator tuning, with a view to briefly replicating the interface biomechanics.

\section{Simulator tuning}

Figure 2 illustrates how the simulator generated the forces and moments of the two phases.

Upmost care was taken to ensure the location of the load cell in the simulator was equivalent to that used during amputee walking tests. Taking the centre of the load cell as the reference frame origin (red dot in Figure 2), a central axis runs along the length of the prosthetic (blue dashed line in Figure 2). The simulator is designed to work on uniaxial test machines and as a consequence, the line of load application (red solid line in Figure 2) runs in a straight line from the connection between the upper plate and the test machine, to the connection between the 
lower plate and the test machine. The line of load application is decomposed onto a twodimensional plane (i.e. sagittal and coronal), as shown by the red dotted lines in Figure $2 a$ and b, respectively. The relative position of the force (red dotted line) in a given plane to the central axis (blue dashed line), effectively determines forces and moments measured by the load cell. The planar angle $\left(\theta_{\text {cor }}\right.$ - black arc in Figure $\left.2 a\right)$ between the in-plane force and central axis are defined as $\theta_{\text {cor }}$ (Figure $2 a$ ) and $\theta_{\text {sag }}$ (Figure $2 b$ ), respectively. $\theta_{\text {cor }}$ determines how the force can be further decomposed into the compression and $M L$ shear, while $\theta_{\text {sag }}$ determines how the force can be distributed between compression and AP shear. The perpendicular distance (black solid line in Figure 2a) from the force in the coronal plane (red dotted line in Figure 2a) to the reference frame origin is the moment arm for coronal bending, while similarly the moment arm in the sagittal plane is shown in Figure $2 \mathrm{~b}$. Altering the relative positions between the upper and lower plates leads to a change in the line of load application and, consequently, the three key load cell outputs could be 'tuned' to be of a similar approximate range to the reference data collected from the amputee tests.

\section{Testing protocol}

In order to investigate the difference between rigid and compliant socket couplings, initially, a rigid aluminium prosthetic pylon (Figure 3a), of the same length $(340 \mathrm{~mm})$ as that of the artificial residuum, was used in place of the residuum on the simulator. The approximate peak vertical GRF obtained during the amputee walking test was used as an input to define a uniaxial compressive load of $850 \mathrm{~N}$ applied to the pylon simulator. The approximate ranges taken from the three key load channels during the amputee walking test were used as guidance, by which to assist the tuning of the simulator. The ball-and-socket joints, between the upper and lower plates and the test machine (Figure 1), allowed rotation to ensure that no damaging moments 
could be transferred to the test machine. This tuning was performed for both WA and PO phases, respectively. Subsequently, the pylon was replaced by the artificial residuum (Figure $3 b-c)$ and simulator was arranged identically to the respective pylon tests. The compression test was performed and the load cell outputs recorded. By comparing all six channels load cell outputs between pylon and artificial residuum scenarios, the effect of the compliant residuum/socket interface to the kinetics were studied.

Further testing was performed to showcase one of the potential applications using such a lab based simulator, i.e. studies of interface stresses during WA and PO phases. Force Sensing Resistors (FSRs) (Interlink Electronics Inc., Westlake Village, CA, USA) were located at the key anatomical loading sites ${ }^{4,5,7}$, namely patella tendon, popliteal depression and fibula head (Figure 3d) on the artificial residuum. The artificial residuum simulator was then tuned so that its key load cell outputs briefly represented similar ranges to those measured during the amputee walking test. Particular attention was made of the measurements in the sagittal plane (e.g. compression, sagittal bending and AP shear) and, in particular, the compression output. The sagittal plane incorporates the vertical direction, thus the kinetics which act to support the body's centre of mass (COM), and the direction of progression, thus the kinetics which act to propel COM forward. The WA and PO phases are the points in the gait cycle where the force required to support the COM (the vertical component of GRF) is at a maximum and the compression output measures the largest components of these supporting forces. Subsequently, pressure measurements from FSRs were recorded and compared with counterparts reported in literature. 


\section{Results}

Rigid vs Compliant socket coupling

Table 1 shows the mean peak values from the load cell outputs, obtained from the pylon and artificial residuum simulator setups, respectively, while the positions of the upper and lower plates were kept the same.

It was clear that the data for the pylon and artificial residuum simulators showed differences in key outputs (Table 1). For example, for the WA phase, the compression force on the load cell was $871 \mathrm{~N}$ for the pylon setup and $787 \mathrm{~N}$ for the artificial residuum setup, representing an approximate $10 \%$ reduction when using a compliant socket coupling. For the PO phase, the sagittal bending was $-56 \mathrm{Nm}$ for the pylon and $-70 \mathrm{Nm}$ for the artificial residuum, representing approximately a $25 \%$ increase in magnitude. Also in the PO phase, AP shear was $157 \mathrm{~N}$ for the pylon but only $104 \mathrm{~N}$ for the residuum, approximately a $34 \%$ reduction (Table 1 ).

There were also large differences in the other load cell outputs. In the WA phase, the ML shear was $-45 \mathrm{~N}$ for the pylon and $-57 \mathrm{~N}$ for the residuum, representing a difference of $27 \%$. In the PO phase, the corresponding values were $-45 \mathrm{~N}$ and $-60 \mathrm{~N}$, representing an approximate $33 \%$ difference. Also in the PO phase, coronal bending changed from $-7 \mathrm{Nm}$ to $-12 \mathrm{Nm}$; approximately a $71 \%$ change (Table 1 ).

Residuum pistoning is a well-recognised feature associated with lower limb amputees ${ }^{26}$. The displacement output from the uniaxial test machine was approximated to a measure of the pistoning. While there was negligible vertical displacement for the pylon setup (all connections 
were rigid), when $850 \mathrm{~N}$ was applied to the artificial residuum maximum vertical displacements of approximately $8 \pm 1 \mathrm{~mm}$ and $12 \pm 1 \mathrm{~mm}$, were recorded for WA and PO phases, respectively.

\section{Interface pressure measurement using the developed simulator}

Figure 4 shows a comparison of the peak values on three key load cell outputs during the amputee walking test and those measured on the tuned artificial residuum simulator. The focus of the tuning was to briefly achieve approximate sagittal plane kinetics, in particular compression output, which was close to the amputee test values. This output (Figure 4a) was reproduced to within $7 \%$ difference for both the WA and PO phases.

Table 2 summarises the ranges of peak pressure measurements recorded from the FSRs when applying a uniaxial load up to a maximum of $850 \mathrm{~N}$, to the artificial residuum simulator. These are compared with reported data by Yeung et al. ${ }^{4}$, adjusting for an amputee of approximately the same weight as the amputee in the present study.

\section{Discussion}

Initially, both the pylon and the residuum simulators had the same upper and lower plate alignments, therefore any differences in load cell outputs, as shown in Table 1, were solely attributed to the presence of the compliant socket coupling introduced by the inclusion of artificial residuum. The residuum consists of silicone mimicking compliant tissue characteristics which, to a certain degree, permit a degree of deformation at the interface. As the uniaxial load was increased to its maximum value of $850 \mathrm{~N}$, the residuum could rotate within the socket, similar to real amputee scenarios ${ }^{27}$. Rotation in the sagittal plane could affect the three key load 
cell outputs (compression, sagittal bending and AP shear) by effectively changing the planar angle between the line of load application, when decomposed onto the sagittal plane, and the load cell central axis $\left(\theta_{\text {sag }}-\right.$ shown by the black arc in Figure $\left.2 b\right)$. This, in turn, meant that the sagittal moment arm changed (black solid line in Figure $2 b$ ). During the WA phase, this rotation increased $\theta_{\text {sag, }}$, in a direction anterior to the central axis (blue dashed line in Figure 2), resulting in a relative change in the nature of the load applied in terms of the compression and shear axes. This was reflected by an increase in magnitude for AP shear, from $-105 \mathrm{~N}$ for the pylon to $122 \mathrm{~N}$ for the residuum and a correspondent decrease in the compression value, from $871 \mathrm{~N}$ for the pylon to $787 \mathrm{~N}$ for the residuum. During the PO phase, the rotation of the residuum in the sagittal plane acted to increase compression (from $886 \mathrm{~N}$ for the pylon to $897 \mathrm{~N}$ for the residuum) while decrease AP shear (from $157 \mathrm{~N}$ for the pylon to $104 \mathrm{~N}$ for the residuum). The sagittal bending also increased in magnitude during $\mathrm{PO}$ (from $-56 \mathrm{~N}$ for the pylon to $-70 \mathrm{~N}$ for the residuum). This was a result of the rotation effectively increasing the length of the sagittal bending moment arm (black solid line in Figure 2).

Possible rotation in the coronal plane during the WA and PO phases could have caused changes in other load cell outputs. In this case, the rotation was in the same direction for both phases, since the line of load application was always medial at the upper plate, relative to the reference frame origin (red dot in Figure 2). This led to an increase in angle between the line of load application, when decomposed onto the coronal plane, and the load cell central axis $\left(\theta_{\text {cor }}-\right.$ black arc in Figure 2a). Consequently, the magnitude of ML shear increased in both phases ($45 \mathrm{~N}$ and $-45 \mathrm{~N}$ for the pylon, compared to $-57 \mathrm{~N}$ and $-60 \mathrm{~N}$ for the residuum - see Table 1 ). It also increased the moment arm in coronal bending (black solid line in Figure 2a), resulting in an 
increase, in the PO phase, in the magnitude of coronal bending between the pylon $(-7 \mathrm{Nm})$ and the residuum $(-12 \mathrm{Nm})$ simulators.

In order to create a simulator setup that mimicked interface dynamics from real amputee walking, the artificial residuum simulator was tuned, with a view to briefly approximate the three key peak load cell outputs to the amputee test. During the simulator tuning, the priority was to focus on compression values, because this axis provides the largest contribution to COM support (Figure 4a), and at the same time ensuring outputs in sagittal bending and AP shear outputs were in similar ranges for amputee tests and simulator setups (Figure $4 b$ and c). Figure 4 shows that AP shear during PO presented greatest difference between the amputee test $(113 N)$ and the simulator $(178 N)$. This is likely because that only the upper and lower plates were used to tune the simulator, while in real amputee scenarios, other effects, such as socket fit and alignment, could also affect the kinetics. Thus, for future work, more comprehensive means to tune the simulator will be investigated by incorporating these effects. Nonetheless, for this study, the simulator was set up, as show in Figure 4, to briefly reproduce amputee walking kinetics so that interface pressure could be studied.

FSR measurements at various residuum locations are shown in Table 2. In the WA phase, the weight of the amputee is largely borne on the posterior region of the residuum ${ }^{28}$, resulting in a high pressure of $101 \sim 187 \mathrm{kPa}$ recorded at the popliteal depression. During the PO phase, however, the weight is transferred to the anterior surface the residuum, leading to highest pressure at the patella tendon (100 188kPa). Additionally, during PO phase, the residuum rotates within the socket in the sagittal plane, so as to produce a 'kicking' action, which propels the prosthetic forwards through swing phase. This rotation results in high pressures at the 
popliteal depression ${ }^{28}(144 \sim 165 \mathrm{kPa})$. The pressure at the fibula head is affected by the mediallateral motion of the body's COM during walking. During WA phase, the body COM is moving laterally ${ }^{29}$, increasing pressure on the fibula head of the residuum $(75 \sim 160 \mathrm{kPa})$. By contrast, during the $\mathrm{PO}$ phase, this pressure is reduced $(100 \sim 137 \mathrm{kPa})$, as the COM moves in a medial direction ${ }^{29}$.

The pressure ranges are similar to those previously reported by Yeung et $\mathrm{al}^{4}$, adapted for an amputee of similar weight (Table 2). Any minor differences could be attributed to the fact that the silicone based artificial residuum may not have proved an exact representation of the soft tissues of the amputee residuum. Additionally, many other factors such as differences in the quality of the fit of the sockets, residuum geometry and prosthetic alignment would have all contributed to differences in measured pressures. Thus, only the approximate ranges of the peak values at the three locations were compared, with a view to demonstrating the brief alignment between simulator interface pressure and clinical amputee tests. Nonetheless, the FSR results suggest that the developed interface simulator provides a good representation of the mechanical loading environment at the residuum/socket interface, which aligns with that experienced in amputee walking tests.

The amount of pistoning measured for the artificial residuum during loaded conditions was approximately $8 \mathrm{~mm}$ and $12 \mathrm{~mm}$ for WA and PO phases, respectively. These values are of similar magnitude to that $(6 \pm 4 \mathrm{~mm})$ previously reported ${ }^{26}$. A degree of variation in displacement range would be predicted as this measure is dependent on many factors, such as socket fit, fluctuations of residuum geometry and volume and prosthetic component alignments etc. It is envisaged that, aside from the total surface bearing socket utilized in this work, it would also be 
interesting to repeat the protocol using other socket and liner types, such as a patella tendon bearing (PTB) socket and a foam liner, with a view to comparing interface biomechanics. It is worth noting that, in comparison to the previously reported simulators, such as the robotic gait simulator $^{14}$, the present system was designed specifically to replicate the WA and PO phases of the gait. Thus, its current design will not reflect temporal changes in loading throughout the complete gait cycle. However, in this work, WA and PO phases were chosen based on ISO 10328 , as GRF reaches peak values in these phases and consequently extreme levels of load are exerted at the residuum/socket interface. The compatibility of the simulator with commonly available test machines facilitates its adoption in a wide range of lab-based tests and studies.

It is thus envisaged that the approach adopted in the development of a residuum/socket interface simulator, could be potentially beneficial to both researchers and clinicians. Such simulators could be applied in lab settings to assess the biomechanical state at the critical residuum/socket interface for lower limb amputees. For example, these results could be used in conjunction with human studies to provide more information regarding interface dynamics. This could then be exploited in Finite Element Analyses to provide a more comprehensive predictive model. Such a simulator could also be used to evaluate socket fit and prosthetic component performance in the clinical setting. Patient-specific artificial residua could be fabricated and the simulator could be used to identify the long-term impact of a particular socket design.

\section{Conclusion}

This work presents a practical approach for the design, fabrication and testing of a lower limb prosthetic simulator, which has the potential to predict biomechanical conditions at the 
residuum/socket interface. Our results suggest that such a simulator can be 'tuned' to simulate walking in stance phase and interface mechanics for specific lower limb amputees. In general, such simulators could be potentially exploited as a lab-based tool to assess interface biomechanics, socket fit, tissue viability etc. without the extensive involvement of amputee participants. This could be particularly advantageous for the assessment of amputees with various comorbidities e.g. gait pathologies and peripheral neuropathy.

\section{Acknowledgements}

The authors would like to thank the UK Medical Research Council (MR/L013096/1) for providing funding and also members of Chas A Blatchford \& Sons Ltd. including Joe McCarthy, Richard Bradbury and Ana Gallego for their help with the fabrication of the artificial residuum and socket for the simulator. All data supporting this study are openly available from the University of Southampton repository at http://doi.org/10.5258/SOTON/403884.

\section{Conflicts of interest}

There are no conflicts of interest in this study.

Word count (Introduction-Conclusion): 4233 


\section{References}

1. Dudek NL, Marks MB, Marshall SC and Chardon JP. Dermatologic conditions associated with use of a lower-extremity prosthesis. Archives of Physical Medicine and Rehabilitation. 2005; 86: 659-63.

2. Sanders JE, Lam D, Dralle AJ and Okumura R. Interface pressures and shear stresses at thirteen socket sites on two persons with transtibial amputation. Journal of Rehabilitation Research and Development. 1997; 34: 19-43.

3. Bader DL, Bouten C, Colin D and Oomens CW. Pressure Ulcer Research: current and future perspectives. Berlin, Heidelberg: Springer Science \& Business Media, 2005.

4. Yeung LF, Leung AK, Zhang M and Lee WC. Effects of long-distance walking on socket-limb interface pressure, tactile sensitivity and subjective perceptions of trans-tibial amputees. Disability and Rehabilitation. 2013; 35: 888-93.

5. Zahedi S. Lower Limb Prosthetic Research In The 21st Century, Atlas of Prosthetics. 2001.

6. Laszczak P, Jiang L, Bader DL, Moser D and Zahedi S. Development and validation of a 3D-printed interfacial stress sensor for prosthetic applications. Medical Engineering \& Physics. 2015; 37: 132-7.

7. Zhang M, Turner-Smith AR, Tanner A and Roberts VC. Clinical investigation of the pressure and shear stress on the trans-tibial stump with a prosthesis. Medical Engineering \& Physics. 1998; 20: 188-98.

8. Convery $\mathrm{P}$ and Buis AW. Conventional patellar-tendon-bearing (PTB) socket/stump interface dynamic pressure distributions recorded during the prosthetic stance phase of gait of a trans-tibial amputee. Prosthetics \& Orthotics International. 1998; 22: 193-8. 
9. Sanders JE, Allyn KJ, Harrison DS, Myers TR, Ciol MA and Tsai EC. Preliminary investigation of residual-limb fluid volume changes within one day. Journal of Rehabilitation Research and Development. 2012; 49: 1467-78.

10. Sanders JE and Fatone S. Residual limb volume change: Systematic review of measurement and management. Journal of Rehabilitation Research and Development. 2011; 48: 949-86.

11. British Standards Institution. Prosthetics - Structural testing of lower-limb prostheses Requirements and test methods. 2006.

12. Bonnet $\mathrm{X}$, Pillet $\mathrm{H}$, Fodé $\mathrm{P}$, Lavaste $\mathrm{F}$ and Skalli W. Finite element modelling of an energy-storing prosthetic foot during the stance phase of transtibial amputee gait. Proceedings of the Institution of Mechanical Engineers, Part H: Journal of Engineering in Medicine. 2012; 226: $70-5$.

13. Neo LD, Lee PV and Goh JC. Principal structural testing of trans-tibial prosthetic assemblies: specimen preparation. Prosthetics \& Orthotics International. 2000; 24: 241-5.

14. De Raeve E, Saey $T$, Muraru $L$ and Peeraer $L$. The use of a robotic gait simulator for the development of an alignment tool for lower limb prostheses. J Foot Ankle Res. 2014; 7: 1-2. 15. Crimin A, McGarry A, Harris EJ and Solomonidis SE. The effect that energy storage and return feet have on the propulsion of the body: A pilot study. Proceedings of the Institution of Mechanical Engineers, Part H: Journal of Engineering in Medicine. 2014; 228: 908-15.

16. King M, Bewes P, Awori N, et al. Primary Surgery: Trauma. Oxford, UK: Oxford Medical Publications, 1987.

17. Krouskop TA, Dougherty DR and Vinson FS. A pulsed Doppler ultrasonic system for making noninvasive measurements of the mechanical properties of soft tissue. Journal of Rehabilitation Research and Development. 1987; 24: 1-8. 
18. Mak AF, Liu GH and Lee SY. Biomechanical assessment of below-knee residual limb tissue. Journal of Rehabilitation Research and Development. 1994; 31: 188-98.

19. Malinauskas M, Krouskop TA and Barry PA. Noninvasive measurement of the stiffness of tissue in the above-knee amputation limb. Journal of Rehabilitation Research and Development. 1989; 26: 45-52.

20. Kerdok AE, Cotin SM, Ottensmeyer MP, Galea AM, Howe RD and Dawson SL. Truth cube: Establishing physical standards for soft tissue simulation. Medical Image Analysis. 2003; 7: 283-91.

21. McGarry A, McHugh B, Duers J and Buis AW. Design of manikin for testing of residuallimb shape-capture method: Technical note. Journal of Rehabilitation Research and Development. 2011; 48.

22. Lowe P. Knee mechanism performance in amputee activity. Ph. D. Thesis (2nd. edn.) University of Strathclyde (May 1969), 1969.

23. Berme N, Lawes P, Solomonidis S and Paul JP. A Shorter Pylon Transducer for Measurement of Prosthetic Forces and Moments during Amputee Gait. Engineering in Medicine. 1975; 4: 6-8.

24. Cunningham DM and Brown GW. Two devices for measuring the forces acting on the human body during walking. Proceedings of the Society for Experimental Stress Analysis. 1952; 9: 75-90.

25. Wolf SI, Alimusaj M, Fradet L, Siegel J and Braatz F. Pressure characteristics at the stump/socket interface in transtibial amputees using an adaptive prosthetic foot. Clinical Biomechanics. 2009; 24: 860-5.

26. Klute GK, Berge JS, Biggs W, Pongnumkul S, Popovic Z and Curless B. VacuumAssisted Socket Suspension Compared With Pin Suspension for Lower Extremity Amputees: 
Effect on Fit, Activity, and Limb Volume. Archives of Physical Medicine and Rehabilitation. 2011; 92: 1570-5.

27. Tang J, McGrath M, Laszczak P, et al. Characterisation of dynamic couplings at lower limb residuum/socket interface using 3D motion capture. Medical Engineering \& Physics. 2015; 37(12):1162-8.

28. Jia X, Zhang M and Lee WCC. Load transfer mechanics between trans-tibial prosthetic socket and residual limb—dynamic effects. Journal of Biomechanics. 2004; 37: 1371-7.

29. Kirtley C. Clinical Gait Analysis - Theory and Practice. Edinburgh: Churchill-Livingstone, 2006. 


\section{Figures}

(a)

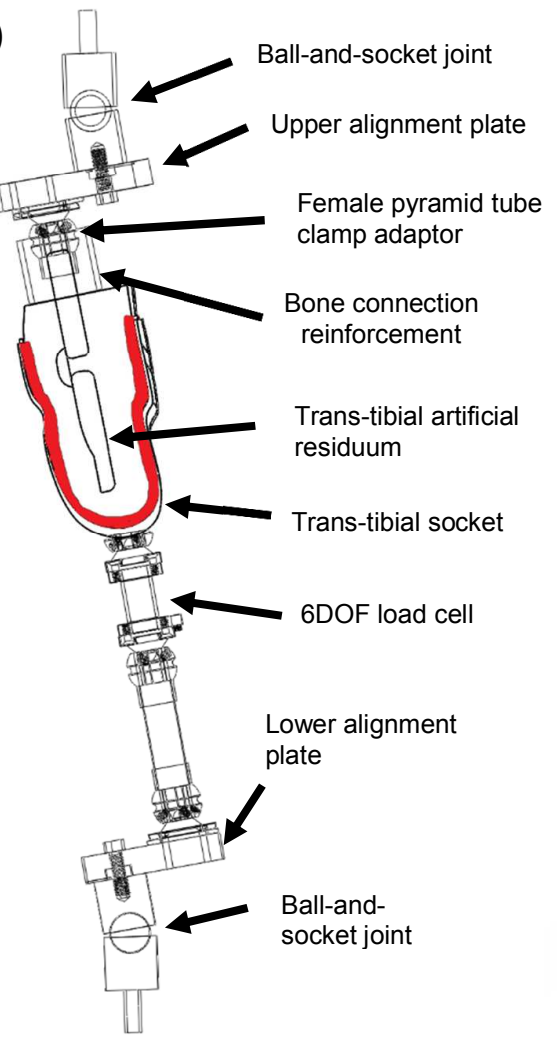

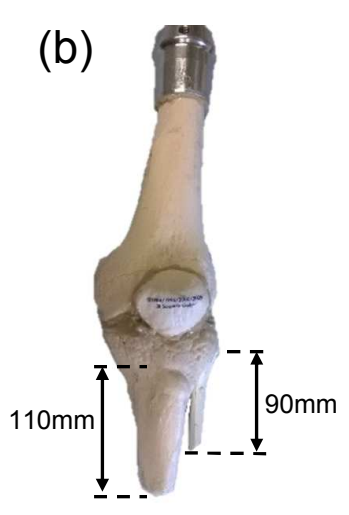

(c)

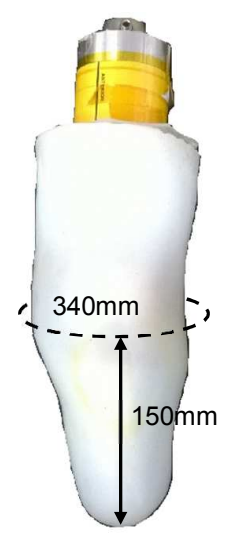

(d)

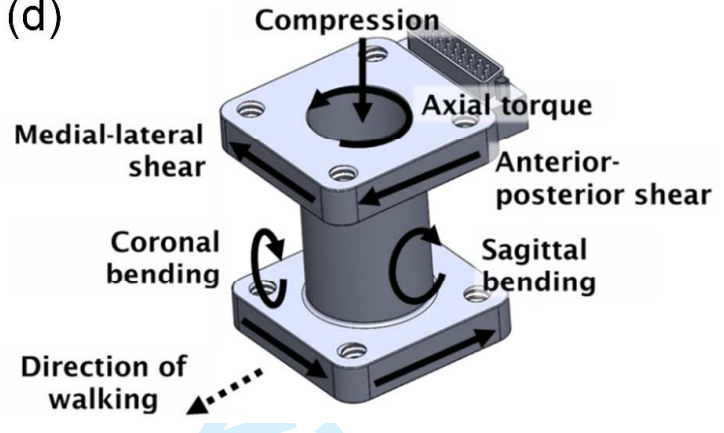

Figure 1. (a) A schematic of residuum/socket interface simulator design, highlighting the residuum/socket interface, (b) the truncated model knee joint, (c) the artificial trans-tibial residuum, and (d) an illustration of the axes and moments measured by the six degree-offreedom (6DOF) load cell. 
(a)

(b)

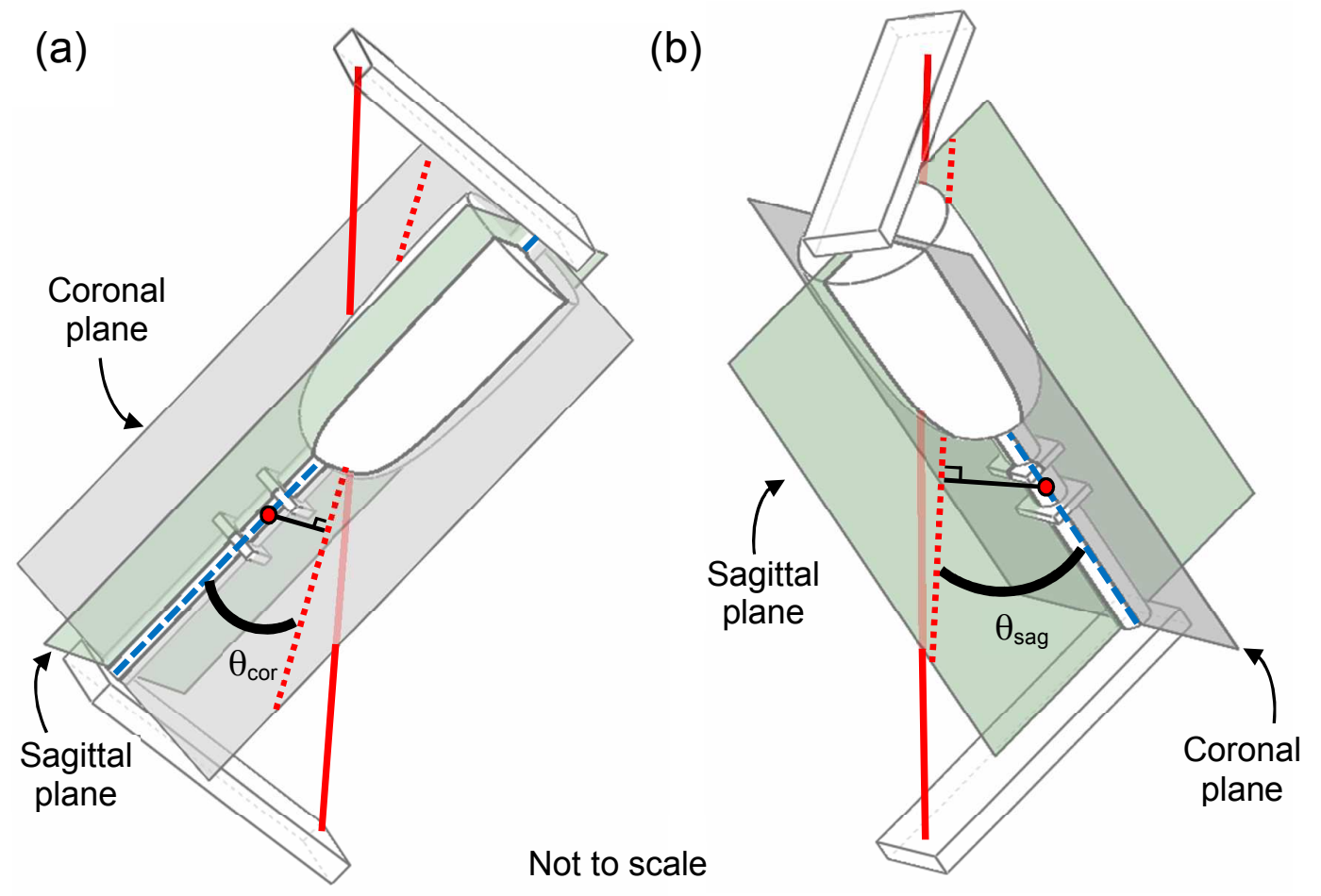

Not to scale

Legend

- Reference frame origin

Line of load application

- ..." Line of load application decomposed onto a plane

-ーーー Load cell central axis Planar moment arm

Figure 2. (a) A schematic of the residuum/socket simulator in the weight acceptance (WA) phase and (b) a schematic of the residuum/socket simulator in the push off (PO) phase. The line of load application is decomposed onto the coronal and sagittal planes. The angles between this planar force and the load cell central axis $\left(\theta_{\text {cor }}\right.$ and $\theta_{\text {sag }}$ for the coronal and sagittal planes, respectively) are shown. The perpendicular distance from this planar force and the reference frame origin is the moment arm. 
(a)

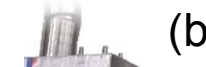

(b)
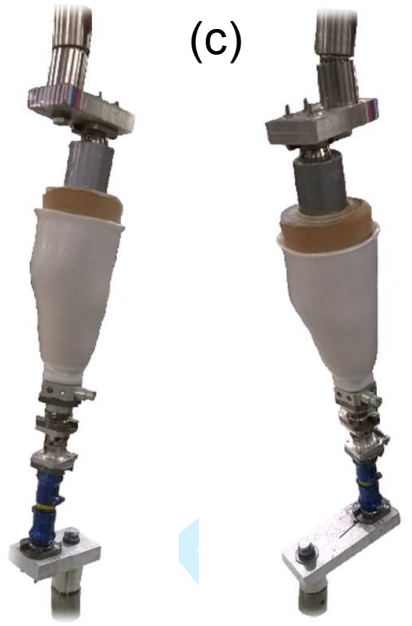

(d)

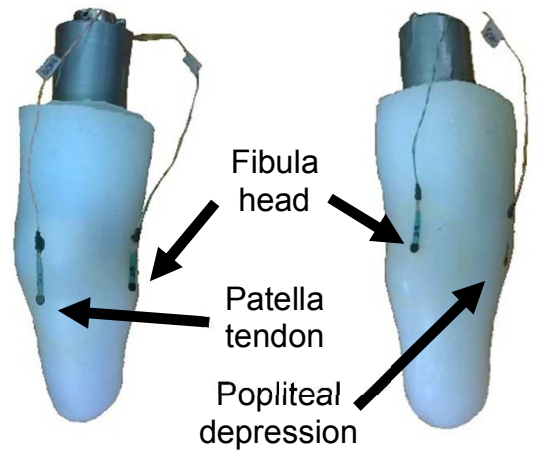

Figure 3. (a) The simulator with a pylon in place of the artificial residuum, (b) the residuum/socket simulator in the weight acceptance (WA) phase, (c) the residuum/socket simulator in the push off (PO) phase, and (d) positions of the force sensing resistors (FSRs) on the artificial residuum. 

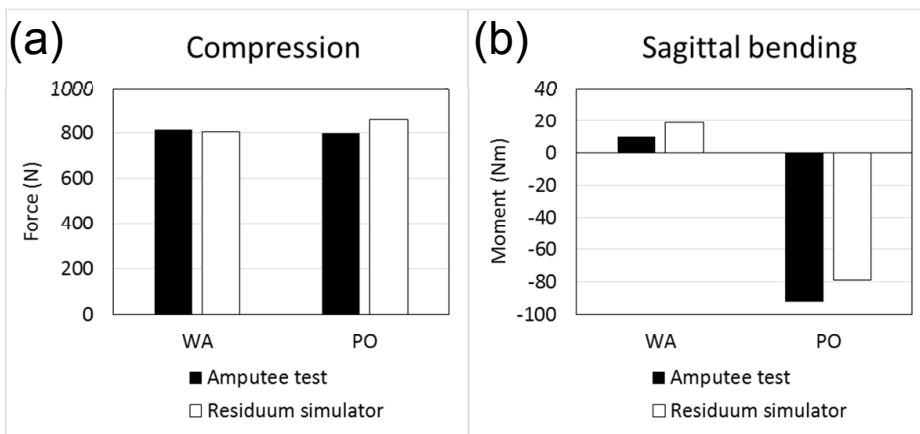

(c) Anterior-posterior shear

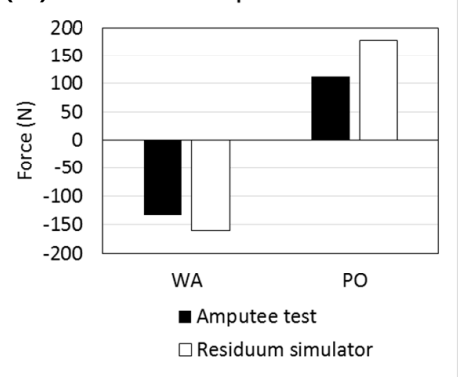

Figure 4. Three key six degrees-of-freedom load cell outputs: (a) compression, (b) sagittal bending, and (c) anterior-posterior (AP) shear. For each output, the charts show the weight acceptance (WA) and push off (PO) mean peak measurements recorded during the amputee walking test (black bars) compared to the artificial residuum simulator (white bars) after it had been 'tuned'. 


\section{Tables}

\begin{tabular}{llll}
\hline $\begin{array}{l}\text { Simulator } \\
\text { phases }\end{array}$ & Load cell outputs & Pylon & $\begin{array}{l}\text { Artificial } \\
\text { residuum }\end{array}$ \\
\hline WA & Compression $(\mathrm{N})$ & 871 & 787 \\
& Anterior-Posterior shear $(\mathrm{N})$ & -105 & -122 \\
& Medial-lateral shear $(\mathrm{N})$ & -45 & -57 \\
& Axial torque $(\mathrm{Nm})$ & 1 & 2 \\
& Sagittal bending (Nm) & 19 & 17 \\
& Coronal bending (Nm) & -11 & -13 \\
PO & Compression (N) & 886 & 897 \\
& Anterior-Posterior shear (N) & 157 & 104 \\
& Medial-lateral shear (N) & -45 & -60 \\
& Axial torque (Nm) & -3 & -3 \\
& Sagittal bending (Nm) & -56 & -70 \\
& Coronal bending (Nm) & -7 & -12 \\
\hline
\end{tabular}

Table 1. Peak values of six degree-of-freedom (6DOF) load cell outputs from the pylon and artificial residuum simulator setups, during weight acceptance (WA) and push off (PO) phases, respectively. 


\begin{tabular}{llll}
\hline $\begin{array}{l}\text { Simulator } \\
\text { phases }\end{array}$ & $\begin{array}{l}\text { Anatomical location } \\
\text { on the residuum }\end{array}$ & $\begin{array}{l}\text { Simulator peak } \\
\text { pressure }(\mathbf{k P a})\end{array}$ & $\begin{array}{l}\text { Yeung et al. peak } \\
\text { pressure }(\mathbf{k P a})\end{array}$ \\
\hline WA & Patella tendon & $87 \sim 117$ & $89 \sim 115$ \\
& Popliteal depression & $101 \sim 187$ & $132 \sim 160$ \\
PO & Fibula head & $75 \sim 160$ & $103 \sim 133$ \\
& Patella tendon & $100 \sim 188$ & $118 \sim 160$ \\
& Popliteal depression & $144 \sim 165$ & $103 \sim 163$ \\
& Fibula head & $100 \sim 137$ & $81 \sim 110$ \\
\hline
\end{tabular}

Table 2. The ranges of FSR peak values measured at different locations of the artificial residuum in comparison with those from real amputee tests by Yeung et $\mathrm{al}^{4}$, adjusted for amputee weight, during weight acceptance (WA) and push off (PO) phases, respectively. 